\title{
Patterns of Physical Activity and Its Impact on Health Risk and Life Satisfaction: An Evidence from Adults in Indonesia
}

\author{
Ali Maksum ${ }^{1, *}$, Nanik Indahwati ${ }^{2}$ \\ ${ }^{1}$ Postgraduate School of Sport Science, The State University of Surabaya, Indonesia \\ ${ }^{2}$ Department of Physical Education, The State University of Surabaya, Indonesia
}

Received July 12, 2021; Revised August 18, 2021; Accepted September 21, 2021

\section{Cite This Paper in the following Citation Styles}

(a): [1] Ali Maksum, Nanik Indahwati, "Patterns of Physical Activity and Its Impact on Health Risk and Life Satisfaction: An Evidence from Adults in Indonesia," International Journal of Human Movement and Sports Sciences, Vol. 9, No. 6, pp. 1087 - 1096, 2021. DOI: 10.13189/saj.2021.090602.

(b): Ali Maksum, Nanik Indahwati (2021). Patterns of Physical Activity and Its Impact on Health Risk and Life Satisfaction: An Evidence from Adults in Indonesia. International Journal of Human Movement and Sports Sciences, 9(6), 1087 - 1096. DOI: 10.13189/saj.2021.090602.

Copyright $\bigcirc 2021$ by authors, all rights reserved. Authors agree that this article remains permanently open access under the terms of the Creative Commons Attribution License 4.0 International License

\begin{abstract}
Along with changes in people's lifestyles, the tendency of non-communicable diseases such as heart attacks, hypertension, and type 2 diabetes is increasing. This condition does not only occur in developed countries, but also in developing countries such as Indonesia. As a result, health costs that must be borne by the state are increasingly high. Sedentary living is suspected to be the main cause of the problem. This research aimed to examine the impact of physical activity on health risk and life satisfaction. The research was conducted in Surabaya and surrounding areas with a total of 529 respondents, consisting of $49.7 \%$ men and $50.3 \%$ women. They were between 40 and 97 with an average of 54.6 years old. Data were collected by questionnaire and analyzed using structural equation modeling. The examination showed that the model was compatible with the data. The test results of the model proved that the value of $\chi^{2} / d f=2.66$, RMSEA $=.056, \mathrm{NFI}=.95$, and $\mathrm{CFI}=.97$. The model explained that involvement in physical activity had a significant effect on decreasing health risks and increasing life satisfaction. The involvement of the participants in physical activities reduced blood pressure, heart rate, obesity, and health problems. Physical activity also increased happiness and reduced stress. Therefore, physical activity needs to be promoted continuously to create a healthier and happier life in easiness and fun.
\end{abstract}

Keywords Health Risk, Life Satisfaction,
Non-communicable Diseases, Physical Activity

\section{Introduction}

During this time, research related to health risks and life satisfaction has been approached more from a medical perspective [1], [2] economic aspects [3], [4] and psychological aspects [5], [6]. There are not many studies examining the problem from the perspective of physical activity done comprehensively. The research is partial and does not enough test evidence that explains the relationship of these variables simultaneously, though physical activity is a cheap and easy way to get healthy, especially in terms of promotive and preventive. In many studies, preventive interventions are proven to save costs 2-3 times compared to the costs incurred on the curative action [7], [8] even in infrastructure it can apply the 80/20 principle [9]. Meta-analysis of 231 studies reporting information on 608 cost-effectiveness health shows that preventive interventions are more effective and cheaper than curative interventions. Overall, preventive costs save 41-59\% compared to curative costs [10].

Research on physical activity and its effects on health risks and life satisfaction are urgent to do to increasing non-communicable diseases in many countries. World 
Health Organization (WHO) report stated that non-communicable diseases such as hypertension, type 2 diabetes, and heart attacks are increasing [11]. It does not only occur in developing countries but also developed countries. Unhealthy lifestyles, such as smoking, drinking alcohol, low-fiber instant foods, and lack of physical activity are suspected as the main triggers of this problem. Non-communicable diseases will continue to be a global concern through the SDGs program as global commitments weaken, both in terms of policy and budget [11], [12]. In 2014, WHO conducted a global survey and made a profile report for each country related to non-communicable diseases. In the case of Indonesia, WHO noted that non-communicable diseases caused death by $71 \%$. There is a significant increase in cases from year to year. In 1995, the death rate due to non-communicable diseases was $41.7 \%$, in 2001 it was $49.9 \%$, and in 2007 it was $59.5 \%$ [11]. From a gender perspective, cardiovascular disease, chronic respiratory illness, and cancer are more common in men than women. Meanwhile, for type 2 diabetes, women suffer more than men. The report also states that risk factors for adults occur due to certain conditions like smoking, high blood pressure, and obesity.

Type 2 diabetes is the third leading cause of death after coronary heart disease and stroke. The prevalence of diabetes has increased from time to time. In 2007 the prevalence was $5.7 \%$ and became $6.9 \%$ in 2013. Indonesia was ranked $6^{\text {th }}$ in the world with 10.3 million people [13]. WHO estimates that if the disease is not handled seriously, then by 2030 thefigure will jump dramatically to 21.3 million people [11]. There are unfavorable conditions for Indonesia because of the habit of excessive rice consumption. This is because rice is the worst type of carbohydrate compared to corn, cassava, and potatoes. Rice consumption per capita in Indonesia is the highest in the world which is $124 \mathrm{~kg} /$ year [14]. Meanwhile, countries such as Thailand and Malaysia are $80 \mathrm{~kg} / \mathrm{year}$, China is 60 $\mathrm{kg} /$ year, Japan is $50 \mathrm{~kg} / \mathrm{year}$, and Korea is $40 \mathrm{~kg} / \mathrm{year}$. The most obvious impact related to the increase in non-communicable diseases is the increase in the National Health Insurance (BPJS Kesehatan) budget far above normal. Participant fees received by the BPJS Kesehatan cannot cover the budget that must be spent to pay for the sick, so they tend to continue to suffer losses [15]. In 2019, the BPJS Kesehatan was estimated to have a budget deficit of 32 trillion [16]. The biggest portion of the budget was spent on non-communicable diseases such as heart disease, kidney disease, diabetes, and stroke. Evaluation of the implementation of BPJS Kesehatan showed that the number of sick people reached $65 \%$ far exceeding the normal standard of $10-15 \%$ of the total population. This disease is generally caused by unhealthy lifestyles, including due to lack of physical activity. The imbalance between food intake and energy burned can cause obesity, which is a simple indicator of the greater size of the stomach circumference. People who are obese have the potential to suffer cardiovascular disease [12]. Such conditions are certainly very detrimental to the country in the long run. Therefore, it needs to be rethought whether the treatment strategyis curative by providing as many health services as possible or is promotive and preventive by providing adequate infrastructure so that the community can carry out physical activities optimally [4], [12] so that the number of sick people decreases.

Aside from physical health, mental issues are also crucial. Referring to WHO data, around 35 million people suffering from depression, 60 million people are affected by bipolar disorder, 21 million people are affected by schizophrenia, and 47.5 million suffer from dementia [17]. What about Indonesia? The results of basic health research in 2013 showed that 14 million (6\%) Indonesians aged 15 years old and over had symptoms of depression and mental disorders. Meanwhile, severe mental disorders such as schizophrenia reach 400 thousand people or 1.7 per thousand populations [18]. Along with the increasingly complex life problems, including volatility, uncertainty, complexity, and ambiguity, which have recently been widely discussed, an increase in the number of people with mental disorders will burden the country's finances and have implications for long-term productivity decline.

The fundamental question is how does the contribution of physical activity in terms of providing solutions to overcome a number of these problems? Some research results prove that increased participation in physical activity can reduce health costs. Research in several countries tries to calculate the economic burden that must be borne by the state due to physical inactivity. In the UK, the direct costs to be borne by the government to treat overweight, obesity, and morbidity in 1981 ranged from $£ 479.3$ million to $£ 4.2$ billion in 2007 [3]. Estimated indirect costs, ie costs arising from the impact of obesity on a wider range such as loss of productivity, ranging from $£ 2.6$ billion to $£ 15.8$ billion. Projection of theoretical models shows that indirect costs reached $£ 27$ billion in 2015. In 2006/2007, obesity-related illnesses are estimated to cost $£ 148$ million for hospitalization. In Scotland, the total social costs for obesity and overweight in 2007/2008 were estimated to be between $£ 600$ million and $£ 1.4$ billion. Research in the United States related to direct health costs that must be borne by the state due to physical inactivity of $\$ 29$ billion in 1987 and to $\$ 76.6$ billion in 2000 [19]. If adults in America increase their involvement with physical activity by $10 \%$, then estimated to save $\$ 5.6$ billion. Studies in China that try to calculate the total economic burden of physical inactivity, which combines medical and non-medical costs of five non-communicable diseases show that physical inactivity contributes $12 \%$ to $19 \%$ to the risk of coronary heart disease, stroke, hypertension, cancer, and type 2 diabetes. Physical inactivity imposes a serious economic burden on 
China because it spends more than $15 \%$ of the country's annual medical and non-medical costs [20].

There is a positive relationship between involvement in physical activity and one's health condition, including mental health. Those who are actively involved in sports show a higher level of confidence than those who are not involved. When teenagers are involved in competitive sports, it turns out that more positive self-concept than those who are not involved in competitive sports. Positive self-concept appears not only in physical dimensions but also in social and intellectual development. Sports are also able to increase stress resistance [21]. Study results proved that adolescents who engage in physical activity are more resilient and able to cope with stressors from their environment. As we know, teenage life is very vulnerable to psycho-social problems, such as the temptation to use drugs, alcohol, promiscuity, and other social ills. The right approach for them is an investment in human resource development in the future.

Although there have been studies examining the effect of physical activity on health and psychological aspects, there is not enough research that examines these variables together. This study aims to develop a theoretical model that explains the simultaneous relationship, both direct and indirect, between physical activity with health risk and life satisfaction. A healthy and happy life is the ultimate goal of every human being and is the main target of sustainable development goals [22].This study provides evidence-based on the influence of physical activity on higher-quality human life. Therefore, the results of this study are beneficial for the government and society to find effective, simple, and inexpensive ways to achieve a happy life and avoid excessive stress and deadly diseases.

\section{Methods}

\section{Participants}

This research is non-experimental using survey methods, which collect data and information from a large number of participants through a questionnaire. As participants were residents of Surabaya and surrounding areas aged 40-97 with an average age of 54.6 years old. This age group is vulnerable in terms of health risks and psychological impact along with the decline in organ function and the burden of life that must be borne by the family. Total participants were 529 people consisting of $49.7 \%$ men and $50.3 \%$ women. From the education level, most of the participants were senior high school graduates (37.2\%), followed by elementary schools (26.8\%), higher education (21.6\%), and junior high schools (14.4\%).

\section{Instruments and Procedures}

Data collection was carried out using a questionnaire. Physical activity variables were measured using a modified physical activity questionnaire [23]. The questionnaire was developed based on the concept of FIT - Frequency, Intensity, and Time [24]. Frequency refers to how often an individual engages in physical activity in one week. Intensity refers to how hard individuals practice during periods of physical activity. Time refers to the duration used in physical activity. The score in the instrument ranges from 0 (no physical activity) to $5(\geq 120$ min per exercise).

Health risk variables were measured based on physical health problems or somatic symptoms. In this concept, health risks suffered by individuals are based on indicators of blood pressure, heart rate or rest, body weight, and self-perceived health. Blood pressure (systole) is the tension when the heart pumps blood throughout the body, which is an important indication of hypertension in a person. Individuals are said to have hypertension if their blood pressure exceeds $140 / 90 \mathrm{mmHg}$. Heart rate is the number of heartbeats on the unit of time which is usually expressed in minutes. A slow heart rate when a person is not doing physical activity indicates that his heart is efficient and has good heart and lung health. Bodyweight refers to individual body weight in $\mathrm{kg}$. Excessive weight (overweight and obese) indicates the amount of fat in an individual's body is immoderate. This condition has the potential to cause other chronic diseases such as diabetes and heart disease. Meanwhile, self-perceived health refers to an individual's perception of his health concerningdaily activities undertaken [25].

The variable life satisfaction refers to the extent to which individuals feel happy and free from the pressures of life that cannot be controlled. There are two indicators used to measure life satisfaction, namely happiness and stress. Happiness variables are measured using the subjective happiness scale [26] and stress variables are measured using the perceived stress scale [27]. Before data collection, participants have explained the purpose of the study and how to fill out a questionnaire. Participants filled out a questionnaire for about 20 minutes and continued with measuring health indicators such as blood pressure and pulse.

\section{Data Analysis}

Data analysis was carried out in two ways. To test the differences between groups, an analysis of variance (ANOVA) was used, statistical analysis to examine the differences in the groups and between groups simultaneously [28]. To test the proposed theoretical model, a structural equation modeling (SEM) method is used, which is a confirmatory multivariate statistical technique to test the structural relations of several variables simultaneously [29]. The final result of SEM is a theoretical model, which is a summary of theories that describe the interrelations between variables that are normally expressed in mathematical formulations. A model is said to be good if it can explain the actual phenomenon with a small error. To test the suitability of 
the theoretical model with the data using the goodness of fit test. If the null hypothesis is accepted, which means there is no difference between the model and the data, the proposed theoretical model is fit to explain the data. If an appropriate model has been obtained, then each hypothesis can be tested which shows the impact of a variable on other variables. The testing criteria are based on a small chi-square with $p \geq .05$, the goodness of fit index (GFI) $\geq 0.90$, the adjusted goodness of fit index (AGFI) $\geq 0.90$, and the root mean square error of approximation (RMSEA) $\leq 0.08$ [29]. Data were processed with the help of IBM Amos 23.0 software.

\section{Results}

Data analysis showed that the level of the respondent's physical activity, in general, was still relatively low. In terms of frequency, $52 \%$ of them did not do physical activity, $13 \%$ do physical activity 1 time per week, $10 \%$ do it 2 times per week, $13 \%$ do it 3 times per week, and 13\% do 4-7 times per week. From the duration aspect, $52 \%$ of them do not involve physical activity, $17 \%$ do physical activity for $0-30 \mathrm{~min}$ per exercise, $25 \%$ do it for $30-60 \mathrm{~min}$, $4 \%$ do it for $60-90 \mathrm{~min}$, and $1 \%$ doit for $90-120 \mathrm{~min}$. From the intensity aspect, $52 \%$ of them did not involve physical activity, $16 \%$ did the light physical activity, 29\% did it with moderate intensity, and 3\% did it with high intensity. The data showed that physical activity had not become a rational choice and had not become a habit of individuals for an active and healthy lifestyle.

The pattern of physical activity undertaken by respondents did not correlate with their age. Physical activity tends to stagnate after individuals enter productive age, which is $\geq 40$ years old. In terms of gender, there were no significant differences in the patterns of physical activity between men and women (see Table 1). At the age of 40 years old and over, besides the decreasing trend of physical activity, there is also no polarization of activity between men and women. Respondents in this age group focus more on economic-based activities. Much time is spent on work so that physical activities such as sports become neglected. This is different from the pattern of physical activity at the age of children and adolescents. Although there are no gender differences in physical activity patterns, there are inter-correlations between dimensions of physical activity. Frequency correlates with the intensity of .69 at $p<.01$ and correlates with the duration of .66 at $p<.01$. The intensity variable correlates with the duration with a coefficient of .87 at $p<.01$. The data shows that individuals who have a strong intention to carry out physical activities, then the indicator frequency, intensity, and duration, will go hand in hand.

Table 1. The differences in physical activity between male and female

\begin{tabular}{|c|c|c|c|c|c|c|}
\hline & & Sum of Squares & df & Mean Square & $\mathbf{F}$ & Sig. \\
\hline \multirow{3}{*}{ Frequency } & Between Groups & 6.672 & 1 & 6.672 & 1.547 & .214 \\
\hline & Within Groups & 2273.064 & 527 & 4.313 & & \\
\hline & Total & 2279.735 & 528 & & & \\
\hline \multirow{3}{*}{ Time/duration } & Between Groups & .135 & 1 & .135 & .128 & .721 \\
\hline & Within Groups & 555.767 & 527 & 1.055 & & \\
\hline & Total & 555.902 & 528 & & & \\
\hline \multirow{3}{*}{ Intensity } & Between Groups & .342 & 1 & .342 & .387 & .534 \\
\hline & Within Groups & 465.503 & 527 & .883 & & \\
\hline & Total & 465.845 & 528 & & & \\
\hline
\end{tabular}


Table 2. The differences in physical health risk and life satisfaction between male and female

\begin{tabular}{|c|c|c|c|c|c|c|}
\hline & & Sum of Squares & df & Mean Square & $\mathbf{F}$ & Sig. \\
\hline & Between Groups & 200.926 & 1 & 200.926 & 12.653 & .000 \\
\hline \multirow[t]{3}{*}{ Body mass index } & Within Groups & 8368.924 & 527 & 15.880 & & \\
\hline & Total & 8569.850 & 528 & & & \\
\hline & Between Groups & 1609.152 & 1 & 1609.152 & 3.670 & .056 \\
\hline \multirow[t]{3}{*}{ Blood pressure } & Within Groups & 231076.799 & 527 & 438.476 & & \\
\hline & Total & 232685.951 & 528 & & & \\
\hline & Between Groups & 4.529 & 1 & 4.529 & .046 & .830 \\
\hline \multirow[t]{3}{*}{ Heart rate } & Within Groups & 51418.072 & 527 & 97.567 & & \\
\hline & Total & 51422.601 & 528 & & & \\
\hline & Between Groups & 12.209 & 1 & 12.209 & 13.641 & .000 \\
\hline \multirow[t]{3}{*}{ Perceived health } & Within Groups & 464.494 & 519 & .895 & & \\
\hline & Total & 476.702 & 520 & & & \\
\hline & Between Groups & .014 & 1 & .014 & .166 & .684 \\
\hline \multirow[t]{3}{*}{ Happiness } & Within Groups & 44.447 & 527 & .084 & & \\
\hline & Total & 44.461 & 528 & & & \\
\hline & Between Groups & .520 & 1 & .520 & 3.302 & .070 \\
\hline \multirow[t]{2}{*}{ Stress } & Within Groups & 83.034 & 527 & .158 & & \\
\hline & Total & 83.554 & 528 & & & \\
\hline
\end{tabular}

Related to health risk indicators, there are data on body weight, systole, heart rate at rest, and perceived health. The results of data analysis showed that the respondent's weight ranged from $32-98 \mathrm{~kg}$ with an average of $62.54 \mathrm{~kg}$. Referring to the BMI category, those who have a body with a thin and normal size were $67.5 \%$, the overweight category is $22.7 \%$, and the obese category is $9.8 \%$. Those who are categorized as overweight and obese are certainly important concerns because of the risk and potential for heart disease and diabetes. Systole ranged between 89-228 $\mathrm{mmHg}$ with an average of $135.20 \mathrm{mmHg}$. This study intentionally uses systole as a measure because systole is more sensitive than diastole. Referring to the research results, systole scores $\geq$ of $140 \mathrm{mmHg}$ are considered high and have a risk of cardiovascular disease. Data analysis shows that $41.2 \%$ of respondents had blood pressure (systole) above $140 \mathrm{mmHg}$. Meanwhile, the heart rate at rest ranges from $50-130$ beats/min with an average of 80.65 beats $/ \mathrm{min}$. This figure is relatively reasonable because the normal category for heart rate is $60-100$ beats/min. Meanwhile, related to respondents' perceptions of their health, $29 \%$ stated they were rarely sick, $61.9 \%$ stated they were often sick, and $9.1 \%$ stated that they were very sick. The high frequency of those who are often sick is strongly suspected to be related to the age of respondents who are not young anymore, wherethe organs of the body have decreased functionally.

In terms of health risk, the difference between men and women occurs in the dimensions of BMI and perceived health (see Table 2). Women were higher in terms of BMI compared to men. Women faced health problems more often than men. The high health problems in women are thought to be due to domestic busyness and family responsibilities. Overweight in female respondents allegedly due to lack of physical activity and an imbalance between food intake and energy expended. Regarding life satisfaction, there were no significant differences between men and women (see Table 2). Life satisfaction between men and women is relatively the same. Life satisfaction which is marked by happiness and stress management is closely related to satisfaction at work and problem-solving skills in the family.

Then, what is the structural relationship model between variables physical activity, health risk, and life satisfaction? The results of data analysis using SEM prove that the theoretical model formulated is compatible with empirical data. The model can explain the structural relationship between variables simultaneously, which is indicated by the value $\chi^{2} / \mathrm{df}=2.66, \mathrm{RMSEA}=.056$, $\mathrm{NFI}=.95$, and $\mathrm{CFI}=.97$ (see Figure 1). These indicators are following the criteria for testing the model in SEM. Partially, it can be explained that physical activity negatively affects health risk with a regression coefficient of -.27 at $p<.001$. That is, the higher the physical activity, the lower the health problems faced by individuals. Or if reversed, the lower the physical activity carried out by individuals, the higher the health problems faced. 


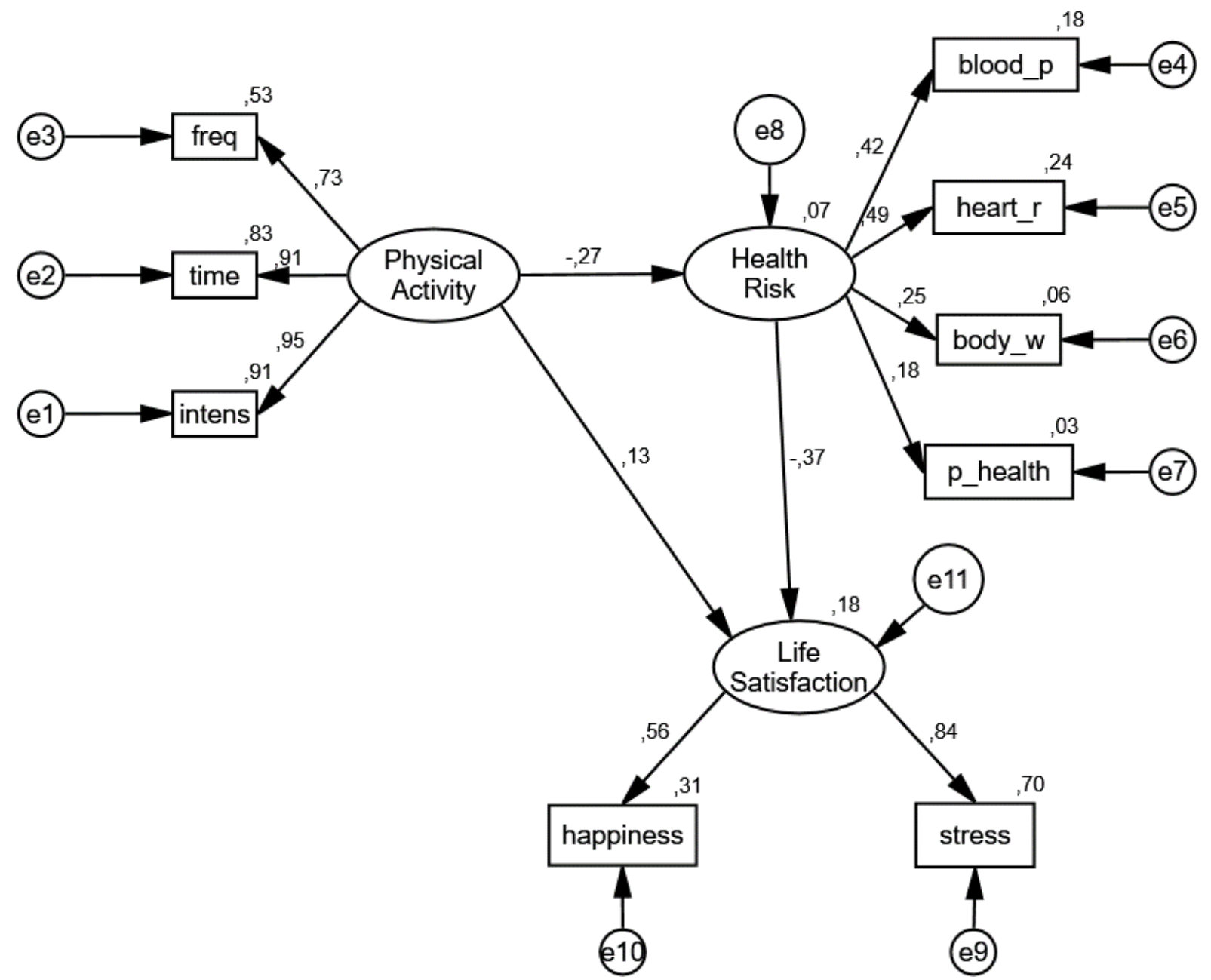

Note: freq= frequency; intens= intensity; blood_p= blood pressure, heart_r= hearth rate, $p \_$health= perceived health. Fits measurement: minimum fits function $\chi^{2} / d f=2.66$, Root Mean Square Error of Approximation (RMSEA) $=.056$, Normed Fit Index $(\mathrm{NFI})=.95$, and Comparative Fit Index $(\mathrm{CFI})=.97$

Figure 1. The causal structure of physical activity, health risk, and life satisfaction

Table 3. Effect size is adjusted the structural equation model

\begin{tabular}{|c|c|c|c|c|c|c|c|c|c|}
\hline \multirow{3}{*}{ Endogenous Variables } & \multicolumn{9}{|c|}{ Exogenous Variables } \\
\hline & \multicolumn{3}{|c|}{ Physical Activity } & \multicolumn{3}{|c|}{ Physical Health Risk } & \multicolumn{3}{|c|}{ Life Satisfaction } \\
\hline & DE & IE & TE & DE & IE & TE & DE & IE & TE \\
\hline Physical health risk & $-.27 * *$ & & $-.27 * *$ & - & - & - & - & - & - \\
\hline Life satisfaction & $.13^{*}$ & $.10^{*}$ & $.23^{* *}$ & $-.37 * *$ & - & $-.37 * *$ & - & - & - \\
\hline Happiness & - & $.13^{*}$ & $.13^{*}$ & - & $-.21 * *$ & $-.21 * *$ & $.56^{* *}$ & - & $.56^{* *}$ \\
\hline Stress & - & $.19^{*}$ & $.19^{*}$ & - & $-.31 * *$ & $-.31 * *$ & $.84 * *$ & - & $.84 * *$ \\
\hline Perceived health & - & $-.05^{*}$ & $-.05 *$ & $.18^{* *}$ & - & $.18^{* *}$ & - & - & - \\
\hline Obesity & - & $-.07 *$ & $-.07 *$ & $.25 * *$ & - & $.25^{* *}$ & - & - & - \\
\hline Heart rate & - & $-.13 * *$ & $-.13 * *$ & $.49^{* *}$ & - & $.49^{* *}$ & - & - & - \\
\hline Blood pressure & - & $-.11 * *$ & $-.11^{* *}$ & $.42 * *$ & - & $.42 * *$ & - & - & - \\
\hline Frequency & $.73^{* *}$ & - & $.73 * *$ & - & - & - & - & - & - \\
\hline Time/duration & $.91^{* *}$ & - & $.91^{* *}$ & - & - & - & - & - & - \\
\hline Intensity & $.95^{* *}$ & - & $.95^{* *}$ & - & - & - & - & - & - \\
\hline
\end{tabular}

Note: $\mathrm{DE}=$ direct effect, $\mathrm{IE}=$ indirect effect, $\mathrm{TE}=$ total effect; $* p<.05, * * p<.01$. Fits measurement - minimum fits function $\chi^{2} / d f=2.66, \mathrm{RMSEA}=.056$, $\mathrm{NFI}=.95$, and $\mathrm{CFI}=.97$ 
Physical activity variables were sequentially contributed by the intensity variable with a regression coefficient of .95 at $\mathrm{p}<.001$, the duration variable with a regression coefficient of .91 at $p<.001$, and the frequency variable with a regression coefficient of .73 at $p<.001$. Health risk variables were sequentially contributed by the heart rate variable with a regression coefficient of .49 at $p<.001$, systole variable with a regression coefficient of .42 at $p<.001$, a bodyweight variable with a regression coefficient of .25 at $p<.001$, and the perceived health variable with a regression coefficient of .18 at $p<.001$. This study also found that there was a positive effect of physical activity on life satisfaction with a regression coefficient of .13 at $p=.029$. That is, the higher the physical activity, the higher the individual's life satisfaction. Conversely, the lower the physical activity, the lower the level of life satisfaction of individuals. Life satisfaction variables were subsequently contributed by the stress variable with a regression coefficient of .84 at $p<.001$ and a happiness variable with a regression coefficient of .56 at $p<.001$. The data showed that life satisfaction is largely influenced by how to manage stress in everyday life.

The results of data analysis also showed that there was a negative effect of health problems on life satisfaction with a regression coefficient of -.37 at $p<.001$. That is the higher the health problem, the lower the individual's life satisfaction. Or conversely, the lower the individual's health problems, the higher the individual's life satisfaction. This fact can be predicted in reasonable logic, a person suffering from illness such as hypertension and diabetes can cause prolonged stress and ultimately affect the satisfaction of his life.

In SEM logic, besides having a direct influence on one variable against another, there is also an indirect effect from one variable to another (see Table 3). For example, there is an indirect relationship between physical activity and life satisfaction of .10 at $p<.05$, with a happiness variable of .13 at $p<.05$, and with a stress variable of .19 at $p<.05$. Likewise, the health risk variable has an indirect relationship with the happiness variable of -.21 at $p<.01$, with the stress variable of -.31 at $p<.01$. Overall, the structural relationship model between variables is fitted, which means that it is supported by empirical data.

\section{Discussion}

This research has provided strong empirical evidence related to the structural relationship between physical activity, health risks, and life satisfaction. A physical activity carried out regularly - for example, frequency three times or more a week, every time exercise $\geq 30 \mathrm{~min}$ with moderate intensity - can reduce health risks and increase individual satisfaction. Although the proportion of physical activity undertaken is not ideal as recommended, it still has a positive impact onindividuals to do. This research found that the level of participation in physical activity is inversely proportional to health risks and is directly proportional to satisfaction in life. The more level of physical activity of a person, the lower the health risk suffered, and the higher the level of life satisfaction. The findings of this study are in line with previous studies which prove that regular physical activity can reduce blood pressure for those who have high blood pressure risk. Research the same thing also shows that someone who doesn't exercise has twice the risk of cancer than someone who actively does sports [20].

This research had proven that physical activity had a positive impact on reducing heart rate, high blood pressure, and overweight. These three things are crucial factors related to non-communicable diseases such as heart attack, stroke, and diabetes. As we know, heart disease is still the number one killer of human deaths in the world until now. A low heart rate indicates that the heart's work is efficient in pumping blood that circulates oxygen and nutrition throughout the body. Conversely, if the rhythm of the heart's work is high, it can trigger heart trouble resulting in heart disease and risks of death. More or less the same thing happens with blood pressure. The findings of this study indicate that $41.2 \%$ of respondents indicated hypertension. This figure is in line with the national prevalence of 45-75 years old reaching $45-63 \%$. This figure can explain why the level of hospital visits continues to increase and BPJS Kesehatan continues to face deficits.If someone has high blood pressure, then he is not only potentially having a heart attack, but also a stroke. Meanwhile, the prevalence of stroke in Indonesia continues to increase. The results of basic health research in 2018 showed that the prevalence of stroke at the age of 60-75 years reached $45-50 \%$ [30]. Other studies conducted in Serbia, Switzerland, and Greece of 410 respondents aged 65-70 years old showed that physical activity has a positive influence on the quality of life of the elderly, which contributes to the health and interpersonal relationships [31].

From the gender aspect, differences only occur in BMI and perceived health. Women are more overweight than men. This finding is in line with national data which states that the prevalence of overweight and obese women in Indonesia is $15.1 \%$ and $29.3 \%$ respectively. Meanwhile, in the male group, the prevalence of overweight and obesity is respectively $12.1 \%$ and $14.5 \%$ [30]. Strong suspicion, this happens because of sedentary habits and eating patterns of less healthy women. This also relates to the number of women who are at home, taking care of domestic problems. BPS-Statistics Indonesia noted that women of productive age who worked were only $48.12 \%$, while men were $77.95 \%$ [32]. Most of the women were in the informal sector. Regarding perceived health, this study found that female groups face more health problems than 
male groups. The complexity of domestic affairs causes women to have insufficient time to relax, thus affecting their health. This fact is in line with research conducted in Spain on retirees and adult housewives who prove that retired men have a far better health status than housewives [25]. Health status here is closely related to physical, mental,and functional conditions.

This study also found that physical activity was positively correlated with life satisfaction. The more actively a person engages in physical activity, the stronger a person's sense of happiness will be. These results are in line with previous studies, which states that health conditions affect mental health and mental health affect life satisfaction [6]. There is a close relationship between stress and happiness [5] and in women, it is very dominant. The higher the stress, the lower the happiness level of one's life. In terms of life satisfaction, there is no significant difference between men and women. This finding is in line with several research results in some countries that there is no difference in the level of satisfaction between men and women.

Although it is believed that physical activity has a positive impact on physical and mental health, not many individuals exercise regularly [33]. This research found that the level of the respondent's physical activity was still relatively low. Based on 3 times per week, the participation rate of respondents' physical activity was $26 \%$. This figure is lower than previous similar studies, which stated that the level of sports participation in Indonesia was 36\% [34]. The low level of participation in physical activity in this study was thought to be due to the age of respondents $\geq 40$ years, which is classified as middle age and adults, where physical activity has declined. Referring to the previous research, physical activity is relatively high at the age of children and adolescents, its peak at the age of 10-19 years old. Entering the age of 20 years and above, the pattern of physical activity is relatively stable and eventually decreases. Physical activity should be the most important step in improving health, not only for adults but for the whole population. Lack of physical activity is a risk factor for chronic diseases such as diabetes, depression, cardiovascular disease, and stroke. If we are regularly involved in physical activity, and even in minimal quantities, it can reduce the risk of many diseases [4], [12].

For largely populated countries such as the USA, China, India, and Indonesia, the findings of this study are urgent because they relate to economic risks in the future. As we know, non-communicable diseases as a result of unhealthy lifestyles have been proven to burden the country's budget three times [7]. Indonesia, which has a population of 270 million people, is very interested in finding efficient and effective strategies to improve the quality of its people, including in the health sector to encourage productivity and the economy. In 2020-2035, Indonesia entered the peak of demographic bonus, where the productive age population is more than the non-productive age population. BPS-Statistics Indonesia noted that the level of dependency of the non-productive population was $47.7 \%$ in 2020 and became $47.2 \%$ in 2025. The lowest dependency peak exists in 2030, which is $46.9 \%$. It means that every 100 people of productive age bear 47 people of non-productive age. After 2035, the demographic bonus will end and Indonesia enters a period of old age population.

We hope that in the future more and more research results will promote the excellence of physical activity in life. If necessary, research is carried out using a neuropsychology approach to convince the public and policymakers. Normally a study, essentially there is no "final word". Opportunities are always available for further research to perfect previous research findings. For example, why is people's physical activity relatively low in almost many countries. What factors cause that to happen. Is physical activity a single variable in influencing health risk and life satisfaction? Or there are otherfactors such as income per capita and level of education that influence it. Once again, further research is important to do.

\section{Conclusions and Recommendations}

This study concluded that the theoretical model that explains the structural relationship between physical activity, health risk, and life satisfaction is compatible with empirical data. Physical activity is an effective predictor to reduce health risks such as high blood pressure, high heart rate, and overweight. Physical activity is also an effective predictor ofincreasing life satisfaction, especially happiness, and releasing stress. Overall, there were no significant differences in physical activity, health risk, and life satisfaction between men and women. In connection with the results of this study, researchers recommend the government allocate adequate funds for physical activity as a form of investment related toimproving the quality of human resources. Public participation in physical activity must continue to be pursued. At any time, preventive and promotive actions are more efficient and effective than curative actions. Physical activity is a nonpharmacological tool to improve the quality of life, including health, psychology, and social. That is why physical activity must be designed as an inexpensive activity so that the whole community can do it.

The impact of Covid-19 which is sweeping across the world should be an important learning for all countries. A clean and healthy lifestyle, including physical activity, becomes urgent in the condition of the epidemic to ward off coronaviruses that attack immunity. Another impact is that the condition of roads and public spaces have been relaxed due to the implementation of the lockdown policy. 
The ecosystem seems to be recovering towards a clean and healthy environment. Paying close attention to this, many big cities in the world aggressively promote walking and cycling to their citizens, especially for short-distance mobility. Along with that, access to pedestrians and cyclists on the highway is increasingly being expanded. This is certainly very encouraging, especially if the campaign is followed by all countries. In addition to having a positive impact on the physical fitness of citizens, it also contributes to creating a clean and pollution-free environment.

Another thing that is also urgent is to diversify physical activity programs by taking into account demographic characteristics, local conditions, economic levels, and so on. As we know, not all regions have enough open space to carry out physical activities. Likewise, not all community members have access to paid sports infrastructure. The basic principle, everyone must have fair access to physical activity without discrimination. At the community level, new awareness must be raised that physical activity is a necessity and therefore needs to be done regularly to fulfill it.

\section{REFERENCES}

[1] S. Beuchat-Mamie, N. Sperisen, P. Molnar, and S. Koçer, "Physical activity and cancer," Praxis (Bern. 1994)., vol. 107, no. 17-18, pp. 965-970, 2018.

[2] F. Sun, I. J. Norman, and A. E. While, "Physical activity in older people: A systematic review," BMC Public Health, 2013.

[3] S. Vuik, A. Lerouge, Y. Guillemette, A. Feigl, and A. Aldea, "The economic burden of obesity," 2019.

[4] OECD, "OECD Reviews of Health Systems: Mexico 2016," 2016.

[5] A. Civitci, "Perceived Stress and Life Satisfaction in College Students: Belonging and Extracurricular Participation as Moderators," Procedia - Soc. Behav. Sci., vol. 205, pp. 271-281, 2015.

[6] D. M. Fergusson, G. F. H. McLeod, L. J. Horwood, N. R. Swain, S. Chapple, and R. Poulton, "Life satisfaction and mental health problems (18 to 35 years)," Psychol. Med., vol. 45, no. 11, pp. 2427-36, 2015.

[7] P. Kansra, "Economic Burden of Diabetes among Women: A Comparison of Outpatient and Inpatient Care," J. Health Manag., vol. 20, no. 3, 2018.

[8] S. L. Szanton et al., "Medicaid Cost Savings of a Preventive Home Visit Program for Disabled Older Adults," J. Am. Geriatr. Soc., vol. 66, no. 3, pp. 614-620, 2018.

[9] C. Stenström, P. Norrbin, A. Parida, and U. Kumar, "Preventive and corrective maintenance - cost comparison and cost-benefit analysis," Struct. Infrastruct. Eng., 2016.

[10] S. Simoens, "Public health and prevention in Europe: Is it cost-effective?," J. Pharm. Heal. Serv. Res., 2011.

[11] World Health Organization, Noncommunicable Diseases Country Profiles 2018. World Health Organization, 2018.

[12] WHO, "Action Plan for the Global Strategy for the Prevention and Control of Noncommunicable Diseases 2008-2013," Geneva World Heal. Organ., 2008.

[13] International Diabetes Federation, IDF Diabetes Atlas Eighth edition 2017. 2017.

[14] World Health Organization, 2014 Mental health atlas. World Health Organization, 2015.

[15] Indonesia Ministry of Health, Indonesia basic health research. Agency of Health Research and Development, 2013.

[16] U.S. Departement of Health and Human Services, "Preventing obesity and cronic diseases through good nutrition and physical activity," 2003.

[17] J. Zhang and J. Chaaban, "The economic cost of physical inactivity in China," Prev. Med. (Baltim)., 2013.

[18] Y. Yang and X. Xiang, "Examine the associations between perceived neighborhood conditions, physical activity, and mental health during the COVID-19 pandemic," Health Place, vol. 67, p. 102505, Jan. 2021.

[19] G. Maugeri et al., "The impact of physical activity on psychological health during Covid-19 pandemic in Italy," Heliyon, vol. 6, no. 6, p. e04315, 2020.

[20] R. Fuchs, "Physical Activity and Health," in International Encyclopedia of the Social \& Behavioral Sciences, 2nd ed., J. Wright, Ed. Elsevier, 2015.

[21] C. J. Huang, H. E. Webb, M. C. Zourdos, and E. O. Acevedo, "Cardiovascular reactivity, stress, and physical activity," Front. Physiol., vol. 4, no. 314, 2013.

[22] T. Lynch, "United nations sustainable development goals: Promoting health and well-being through physical education partnerships," Cogent Educ., vol. 3, no. 1, pp. 1$15,2016$.

[23] World Health Organization, "WHO | Global Physical Activity Surveillance," World Heal. Organ. Media Cent. Fact Sheet No. 311, 2016.

[24] S. A. Billinger, P. Boyne, E. Coughenour, K. Dunning, and A. Mattlage, "Does Aerobic Exercise and the FITT Principle Fit into Stroke Recovery?," Current Neurology and Neuroscience Reports. 2014.

[25] L. Pino-Domínguez et al., "Self-perceived health status, gender, and work status," J. Women Aging, 2016.

[26] E. Diener, R. A. Emmons, R. J. Larsem, and S. Griffin, "The Satisfaction With Life Scale," J. Pers. Assess., vol. 49, no. 1, pp. 71-75, 1985.

[27] S. Cohen, R. C. Kessler, and L. U. Gordon, Measuring Stress: A Guide for Health and Social Scientists. Oxford University Press, 1997.

[28] W. C. Hair, J.H., Anderson, R.E., Tatham, R.L., \& Black, Multivariate data analysis, 5th ed. Prentice Hall, 1998.

[29] B. M. Byrne, Structural equation modeling with AMOS. 
1096 Patterns of Physical Activity and Its Impact on Health Risk and Life Satisfaction: An Evidence from Adults in Indonesia

Basic concepts, applications, and programming. Routledge, 2010.

[30] Indonesia Ministry of Health, Indonesia basic health research. Agency of Health Research and Development, 2018.

[31] E. Samouilidu, S. Pacić, R. Nikić, and F. Eminović, "Physical activity and quality of life of older adults," in Physical Activity Effects on the Anthropological Status of Children, Youth and Adults, F. Eminovic and M. Dopsaj, Eds. Nova Science Pub Inc., 2016.

[32] BPS-Statistics Indonesia, "Keadaan Ketenagakerjaan di
Indonesia 2018 [The State of Employment in Indonesia 2018]," Jakarta, 2018.

[33] T. F. T. Kamalden, S. A. Wickramarachchi, S. K. Geok, and Q. Gasibat, "A systematic review of self-monitoring interventions in promoting physical activity among adolescents in south asian countries," Int. J. Hum. Mov. Sport. Sci., vol. 8, no. 6, pp. 321-328, 2020. DOI: 10.13189/saj.2020.080603.

[34] A. Maksum, Patterns of sports participation by age, gender, and jobs: A case of Indonesia (Research Report). State University of Surabaya, 2020. 